\title{
The impact of geologic variability on capacity and cost estimates for storing $\mathrm{CO}_{2}$ in deep-saline aquifers
}

\author{
Jordan K. Eccles ${ }^{a, *}$, Lincoln Pratson a , Richard G. Newell a, Robert B. Jackson a,b,c \\ a Nicholas School of the Environment, Division of Earth and Ocean Sciences, Duke University, Durham, NC, 27708, USA \\ ${ }^{b}$ Department of Biology, Duke University, Durham, NC, 27708, USA \\ c Center on Global Change, Duke University, Durham, NC, 27708, USA
}

\section{A R T I C L E I N F O}

\section{Article history:}

Received 10 February 2011

Received in revised form 21 November 2011

Accepted 26 November 2011

Available online 14 December 2011

\section{JEL classification:}

Q30

Q31

\section{Keywords:}

Carbon storage

Carbon sequestration

CCS

Geology

Resource evaluation

Marginal abatement

\begin{abstract}
A B S T R A C T
While numerous studies find that deep-saline sandstone aquifers in the United States could store many decades worth of the nation's current annual $\mathrm{CO}_{2}$ emissions, the likely cost of this storage (i.e. the cost of storage only and not capture and transport costs) has been harder to constrain. We use publicly available data of key reservoir properties to produce geo-referenced rasters of estimated storage capacity and cost for regions within 15 deep-saline sandstone aquifers in the United States. The rasters reveal the reservoir quality of these aquifers to be so variable that the cost estimates for storage span three orders of magnitude and average $>\$ 100 /$ tonne $\mathrm{CO}_{2}$. However, when the cost and corresponding capacity estimates in the rasters are assembled into a marginal abatement cost curve (MACC), we find that $~ 75 \%$ of the estimated storage capacity could be available for $<\$ 2 /$ tonne. Furthermore, $\sim 80 \%$ of the total estimated storage capacity in the rasters is concentrated within just two of the aquifers-the Frio Formation along the Texas Gulf Coast, and the Mt. Simon Formation in the Michigan Basin, which together make up only 20\% of the areas analyzed. While our assessment is not comprehensive, the results suggest there should be an abundance of low-cost storage for $\mathrm{CO}_{2}$ in deep-saline aquifers, but a majority of this storage is likely to be concentrated within specific regions of a smaller number of these aquifers.
\end{abstract}

(c) 2011 Elsevier B.V. All rights reserved.

\section{Introduction}

The Intergovernmental Panel on Climate Change (IPCC) projects that to stabilize the atmospheric $\mathrm{CO}_{2}$ concentration between 440 and 485 ppm, global $\mathrm{CO}_{2}$ emissions must peak between 2010 and 2030 and decrease soon thereafter (Bernstein et al., 2007). Energy use is the major contributor to greenhouse gas (GHG) emissions, and although conservation and low-carbon technologies can help reduce emissions, demand for fossil fuels such as coal is increasing (Bernstein et al., 2007). One way that fossil fuel use could continue while constraining GHG emissions is through the implementation of geologic carbon capture and storage (CCS) (Hoffert et al., 2002; IPCC, 2005; Pacala and Socolow, 2004), the possibility of capturing $\mathrm{CO}_{2}$ emissions at large industrial point sources, such as power plants, and transporting the $\mathrm{CO}_{2}$ via pipeline to sites where the GHG would be injected underground into geologic reservoirs for long-term storage.

As a mitigation strategy, CCS will likely see broad-scale deployment only if large quantities of $\mathrm{CO}_{2}$ can be captured and stored at costs equal to or less than other emissions avoidance options. The

\footnotetext{
* Corresponding author. Tel.: + 1919681 6577; fax: +1 9196845833. E-mail address: jordan.eccles@duke.edu (J.K. Eccles).
}

most promising geologic sink for $\mathrm{CO}_{2}$ is saline aquifers. These appear to have tens to hundreds of times the storage potential of other possible onshore $\mathrm{CO}_{2}$ sinks, including coal seams, basalts, and oil and gas reservoirs (IPCC, 2005). How much $\mathrm{CO}_{2}$ can actually be sequestered in saline aquifers has been the subject of a number of studies, as well as a focus of major U.S. and international collaborative research programs (e.g., the U.S. Department of Energy (DOE) National Carbon Sequestration Database and Geographic Information System (NATCARB) and the International Energy Agency Greenhouse Gas R\&D Programme (IEAGHG)). The capacity estimates produced by these and other studies vary considerably (Bachu et al., 2007), but first-order assessments at the global scale (Koide et al. 1992) through more detailed assessments at the continental to national level (e.g., the Indian sub-continent by Holloway et al. (2009) and the USDOE Sequestration Atlas for North America (Department of Energy (DOE), 2010)) repeatedly demonstrate that deep-saline aquifers could store up to centuries worth of current anthropogenic $\mathrm{CO}_{2}$ emissions.

Less clear is the likely cost of this form of storage. Analyses for the United States (Bock, 2002), Europe (Hendriks et al., 2004), and Australia (Allinson et al., 2003) initially suggested storage costs in saline aquifers might be $\$ 0.5-\$ 3 /$ tonne (IPCC, 2005). Subsequent work, however, has projected costs that are higher and/or more variable (AL-JUAIED and Whitmore, 2009; BCG, 2008; Dooley et al., 2008; Eccles et al., 2009; McKinsey Climate Change Initiative, 2008). 
Variability in storage costs is important because it can significantly affect transport costs for CCS. To optimize the overall cost efficiency of a CCS system, transport costs must be traded off against storage costs in such a way as to minimize their combined expense (e.g., Dooley et al. (2008), Gresham et al. (2010), Middleton and Bielicki (2009)). This makes accurate information about storage costs critical.

The value of integrating transport and storage in cost assessments has been demonstrated by efforts ranging from the IEA GHG Programme (Wildenborg et al., 2004) to the SimCCS modeling package developed by Middleton and Bielicki (2009). The integration is achieved by using a transport optimization algorithm to link each $\mathrm{CO}_{2}$ point source in a region to a potential storage reservoir. The total cost of transport and storage is then computed weighted by each firm's emissions. Integrated assessments have produced marginal abatement cost curves (MACCs) for $\mathrm{CO}_{2}$ transport and storage from major point sources in North America (Dooley et al., 2004), Europe (Wildenborg et al., 2004), and China (Dahowski et al., 2009). The curves are built by adding the potential abatement of emissions from each point source to the abatement potential of the other sources in order of increasing cost of transport and storage per tonne of $\mathrm{CO}_{2}$.

Developers of the MACCs acknowledge that the geologic heterogeneity of saline aquifers could lead to storage cost estimates that range over several orders of magnitude (Dooley et al., 2004). However due to lack of data and/or methods for adequately incorporating heterogeneity in reservoir quality, existing MACCs are based on an average or even single estimate of storage capacity and cost per aquifer (Middleton and Bielicki, 2009; Wildenborg et al., 2004); and in some cases the constant values are applied to all the aquifers evaluated (Dahowski et al., 2009; Dooley et al., 2004). Thus cost variations in the MACCs are predominantly the result of varying transport distances between the $\mathrm{CO}_{2}$ point sources and saline aquifers, and do not reflect potential additional variability due to storage.

The assumption that storage capacity and cost are constant within and even among reservoirs is suitable if the reservoirs are small, welldefined and can be adequately characterized by summary statistics, as is the case for many oil and gas fields. However, deep-saline aquifers are large, and spatial variations in their reservoir properties can be significant, leading in turn to significant variations in storage costs. We illustrate that these variations are not adequately represented by single or even average capacity and cost estimates by using a publically available dataset that includes extensive and detailed information on key reservoir properties for 15 deep-saline sandstone aquifers in the United States. We rasterize these data where they are dense enough and then input the rasters into our previously published model (Eccles et al., 2009) to produce corresponding rasters of estimated storage capacity and cost. We then use these rasters to build purely storage-based MACCs, which do not include transport costs from existing $\mathrm{CO}_{2}$ point sources and only describe the resource potential of the aquifers. The rasters and MACCs are not comprehensive assessments of U.S. storage potential, but are inclusive enough to show that estimated storage capacities and costs are not uniformly distributed spatially nor normally distributed statistically. This means that the use of average capacity and cost estimates for entire saline aquifers can grossly misrepresent the true capacity and cost for $\mathrm{CO}_{2}$ storage at many sites within the aquifers. The MACCs also reveal an inverse relationship between estimated storage capacity and cost, one in which the regions analyzed are dominated by relatively high-capacity, low-cost storage sites. This relationship is not so much tied to the surface area of the aquifers as it is to their thickness. Further development of spatially-based storage capacity and cost estimates is needed if transport optimization algorithms are to be used to map out cost-effective configurations for potential pipeline routes connecting $\mathrm{CO}_{2}$ sources to these aquifers and similarly large candidate reservoirs.

\section{Methods}

\subsection{Data}

Our approach to constructing storage-based MACCs involves using geospatially referenced reservoir properties that can be rasterized to represent the aquifers as large, continuous underground entities. This requires that the geologic property data are (1) extensive and dense enough to reveal systematic variations within the aquifer at scales descending to the cell size of the rasters, and (2) that the data include parameters from which storage capacity and cost can be determined. These are particularly challenging requirements for deep-saline aquifers, as they are not as well characterized as oil and gas reservoirs (Bachu et al., 2007). Publicly available GIS data from the NATCARB project was, for example, not adequate for our approach because it satisfied neither requirement. In NATCARB, deep-saline aquifers as well as other candidate reservoirs with spatial extents $>100,000 \mathrm{~km}^{2}$ are represented as homogeneous bodies and are summarized only by total storage capacity (Department of Energy (DOE), 2010). The data on which the capacity estimates are based can be extensive (Department of Energy (DOE), 2010) but rarely include permeability and often lack other similarly critical parameters we need to determine cost using our previously published model (Eccles et al., 2009).

We used data compiled, digitized and made publically available by the Texas Bureau of Economic Geology (BEG) for 15 deep-saline sandstone aquifers located around the United States. These aquifers, outlined in blue in Fig. 1, represent some of the nation's largest sequestration opportunities (Bureau of Economic Geology (BEG), 2000). The aquifers are indexed to Table 1, which identifies the aquifers in terms of the basin in which they are located, the stratigraphic formation or group in which they occur, the total surface area of the aquifer, and how much this area we were able to rasterize.

The BEG data for the aquifers geolocate eight key reservoir properties needed by our capacity/cost model; formation depth, permeability, net sand thickness, formation thickness, temperature, pressure, salinity, and porosity. Unfortunately, temperature, pressure, and/or porosity are sometimes missing from the data records, so where necessary we estimate these parameters using the following published subsurface gradients: for temperature, $25^{\circ} \mathrm{C} / \mathrm{km}$ starting at a surface temperature of $20^{\circ} \mathrm{C}$ (Nordbotten et al., 2005); for pressure, $10.5 \mathrm{MPa} / \mathrm{km}$ (Eccles et al., 2009); and for porosity, the gradient given by Bahr et al. (2001), in which porosity declines exponentially with depth.

We convert the BEG data, which are in various digital formats (see Table A1 in Appendix), into rasters having a grid cell size of $1 \mathrm{~km} \times$ $1 \mathrm{~km}$ (the choice of this resolution is explained in Section 2.2.3). Because most of the BEG data are in the form of isolines and we unaware of the type and density of data used to create the isolines, we simply rasterize them using the ESRI ArcGIS topo-to-raster tool. Data files that are in point form are rasterized by kriging. Where an aquifer is represented as a polygon, we convert it directly into a raster with cell values equal to the value assigned to the polygon.

The variation in the form of the BEG data prevents us from limiting the extent of interpolation in the rasterization process based on underlying data density except in the case of point data (Table A1). For this we rely on the lower limits of the ArcGIS kriging algorithm, which requires a minimum of ten points to create a raster. More importantly, the rasters are not extrapolated beyond the extent of the BEG data.

The end result is a set of rasters of each key parameter that partially cover each sandstone saline aquifer. Storage capacity and cost in an aquifer are only modeled where the rasters of all eight key parameters overlap. These regions correspond to the grey and/or colored areas that lie inside the blue outlines of the aquifers in Fig. 1 and 

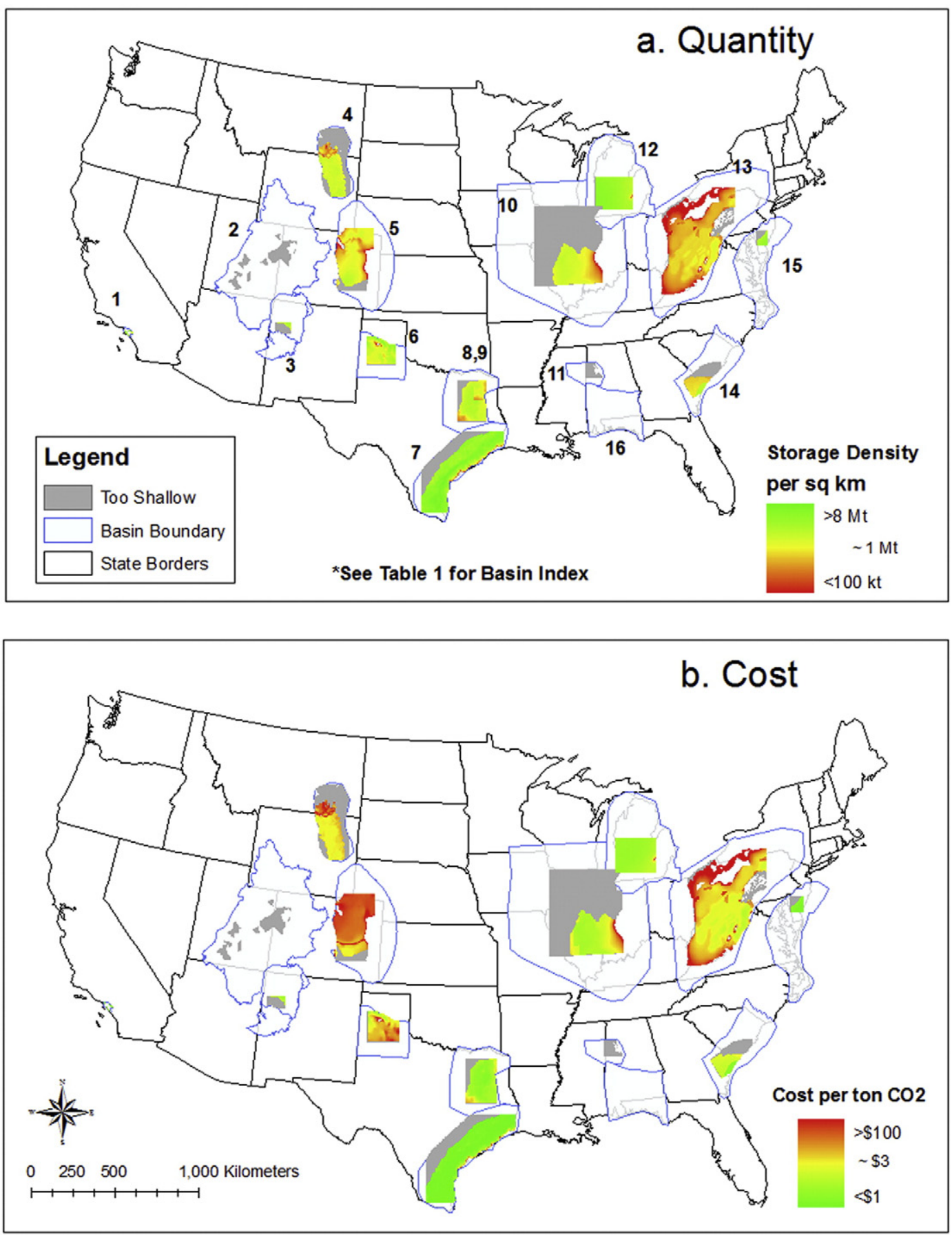

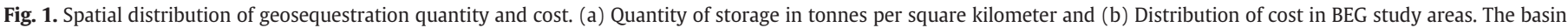

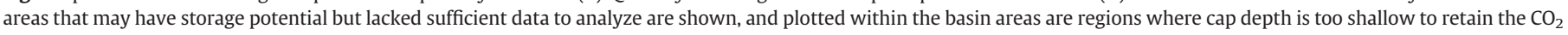
belowground. Although Mt. Simon extends further than indicated on the map, our analysis only included geological data characteristic of the Michigan area.

constitute only $30 \%$ of the roughly $700,000 \mathrm{~km}^{2}$ of combined surface area for all the aquifers.

Note that we restricted our evaluation to sandstone aquifers since our model for estimating storage capacities and costs was developed and calibrated using sandstone injection projects (Eccles et al., 2009). Furthermore, we depict the aquifer as a single layer. In reality, the formations or groups containing the aquifers are multilayered, and in general only the sandy layers with sufficient porosity and permeability serve as part of the aquifer, since muddy layers are too impermeable. The BEG data are not detailed enough to separate out the sandy and muddy layers, so we use the net sand thickness of the formation/group as the "effective" thickness of the aquifer, i.e. the thickness in which $\mathrm{CO}_{2}$ can be stored.

For these and other reasons, our study is not a complete assessment of the potential capacity and cost for storing $\mathrm{CO}_{2}$ in U.S. deepsaline aquifers. Instead it is an analysis of how storage capacity and cost can vary across such aquifers as revealed by our mapping method. For a complete explanation of our interpolation and reconstruction methods for each study area, see Appendix Section A1. 
Table 1

List of analyzed formations and map indices.

\begin{tabular}{|c|c|c|c|c|c|}
\hline Basin & Formation & Surface area $\left(\mathrm{km}^{2}\right)$ & Data coverage & Data coverage $\left(\mathrm{km}^{2}\right)$ & Map index \\
\hline Los Angeles Basin & Repetto Formation & 15,600 & $13 \%$ & 2028 & 1 \\
\hline Sevier Basin & Glen Canyon Group & 371,000 & $29 \%$ & 107,590 & 2 \\
\hline San Juan Basin & Morrison Formation & 49,600 & $6 \%$ & 2976 & 3 \\
\hline Powder River Basin & Fox Hills/Lower Hell Creek & 69,000 & $19 \%$ & 13,110 & 4 \\
\hline Denver Basin & Lyons Sandstone & 170,000 & $38 \%$ & 64,600 & 5 \\
\hline Palo Duro Basin & Granite Wash & 63,800 & $39 \%$ & 24,882 & 6 \\
\hline Texas Gulf Coast & Frio Formation & 138,600 & $76 \%$ & 105,336 & 7 \\
\hline East Texas Basin & Woodbine Formation & 97,500 & $42 \%$ & 40,950 & 8 \\
\hline East Texas Basin & Paluxy Sandstone & 101,300 & $7 \%$ & 7091 & 9 \\
\hline Illinois Basin & St. Peter Sandstone & 568,800 & $26 \%$ & 147,888 & 10 \\
\hline Black Warrior Basin & Pottsville Formation & 24,900 & $10 \%$ & 2490 & 11 \\
\hline Michigan & Mt. Simon Formation & 164,000 & $25 \%$ & 41,000 & 12 \\
\hline Appalachian Basin & Oriskany Formation & 358,000 & $42 \%$ & 150,360 & 13 \\
\hline South Carolina Coastal Plain & Cape Fear Formation & 91,700 & $25 \%$ & 22,925 & 14 \\
\hline Eastern Coastal Plain & Lower Potomac Group & 106,600 & $6 \%$ & 6396 & 15 \\
\hline Alabama Gulf Coastal Plain (missing data) & Tuscaloosa Group & & & & 16 \\
\hline
\end{tabular}

\subsection{Model}

We apply our previously published model (Eccles et al., 2009) to each grid cell in the rasterized regions in Fig. 1 to produce corresponding capacity and cost rasters from which we can then build a storage-based MACC. We recognize that a commercial-scale $\mathrm{CO}_{2}$ storage site will in almost all cases require a reservoir volume with a surface footprint that is much more expansive than the $1 \mathrm{~km} \times 1 \mathrm{~km}$ cell size to which we have rasterized the BEG data. In fact, this surface footprint requirement will vary inversely with the reservoir thickness, increasing where the reservoir thins, and shrinking where the reservoir thickens, which is why we do not assume a fixed storagesite area. Similarly, we do not assume a fixed areal configuration for a storage site, because spatial variability in reservoir quality (e.g., porosity and permeability) will generally lead to an irregular shaped footprint assuming the site is set up to maximize local storage or minimize total costs.

Instead, we assume that the small cell size to which we have gridded the BEG data is representative of the reservoir within and around the cell (i.e., the reservoir is homogeneous and isotropic) in terms of its properties, i.e., thickness, porosity, permeability, etc. We use these properties to calculate the areal footprint that would be required of such a reservoir were it to be injected with a commercial-scale flux of $10 \mathrm{MtCO}_{2} / \mathrm{y}$ (or about what three $500 \mathrm{MW}$ coal-fired power plants emit annually) over $20 \mathrm{y}$. With this footprint and the reservoir properties, we next calculate the average rate at which $\mathrm{CO}_{2}$ can be injected into the reservoir and thus the total number of injection wells that will be needed. Implicit in this calculation is the assumption that injection rates at the wells distributed about this area will not significantly decline over time due to pressure interfere between the wells. We then use the number of wells along with the storage-site footprint to estimate the total cost of storing the $\mathrm{CO}_{2}$ at such a site, including not only the costs for drilling and injection, but also site evaluation, monitoring and remediation. Finally, we divide this total cost by the total $\mathrm{CO}_{2}$ injection rate to arrive at a cost of storage per tonne $\mathrm{CO}_{2}$ that is normalized to the original grid cell. This fractional cost of storage is directly based on the reservoir properties of the grid cell, i.e. it represents the cost of storage for the fraction of the site that would sit atop the cell. In this way, a storage site can be assembled from a group of adjacent cells within our gridded data that together have a configuration that meet the capacity requirements of the site within that area of the grid. Furthermore, the average cost of storing $\mathrm{CO}_{2}$ within the site will be equal to the average normalized cost of all the cells making up the site, while the overall cost will be equal to the sum of the total cost for the cells (i.e. the capacity at the cell times its normalized cost).
As in Eccles et al. (2009), the key modules of our modeling approach estimate (i) the bulk $\mathrm{CO}_{2}$ storage capacity of deep-saline sandstone aquifers, (ii) the maximum rate at which $\mathrm{CO}_{2}$ can be injected into the aquifers, and (iii) the total cost of carrying out this form of storage. We have updated these modules in this study to include several more realistic assumptions for estimating capacities and costs.

\subsubsection{Capacity module}

The capacity module, like that in Eccles et al. (2009), is a relatively simple bulk volume calculation, derived from Bachu et al. (2007). The capacity for a given cell is represented by

$A_{i, j}=v\left(b_{i, j}, r\right) \rho\left(T_{i, j}, P_{i, j}\right) \phi_{i, j} e$

where $A$ is the storage density of $\mathrm{CO}_{2}$ (in tonnes per square kilometer), $v$ is the bulk rock volume, $\rho$ is density of $\mathrm{CO}_{2}$ in tonnes per cubic kilometer, $\phi$ is the rock porosity, $e$ is the capacity factor which, in our case, includes only sweep efficiency, and $i, j$ represent the geospatial coordinates of the cell. Note that $v$ is a function of net sand thickness $b$ and grid cell size $r(1 \mathrm{~km} \times 1 \mathrm{~km})$, and that $\rho$ is a function of temperature $T$ and pressure $P$. Since net sand thickness are given by the BEG data, we use it as an explicit variable in Eq. (1) rather than folding it into the value for $e$. Others use a capacity factor that has been scaled by an assumed net-to-gross ratio of sand and/or cap rock integrity, such as is done in the USDOE Carbon Atlas (Department of Energy (DOE), 2010). Consequently such capacity factors should not be directly compared to ours.

We have improved this part of the model in the calculation of density and in the use of the capacity factor. For density, we now use the equations of state for $\mathrm{CO}_{2}$ published by Span and Wagner (1996) in place of the ideal gas law used in Eccles et al. (2009). The ideal gas law is sufficient for reservoirs at subsurface depths of $<2000-3000 \mathrm{~m}$, but overestimates $\mathrm{CO}_{2}$ density and thus underestimates storage costs in reservoirs that are deeper. The equations of state now provide accurate estimates of $\mathrm{CO}_{2}$ density for reservoirs at all depths.

The other change to this module is the inclusion of the capacity factor in Eq. (1). We set this factor to $4 \%$ based on computer modeling by Doughty et al. (2001) for a saturated homogenous reservoir in which $\mathrm{CO}_{2}$ storage has been maximized. This value is near the upper limit used in NATCARB by the DOE (0.5-5.5\%) (2010) but within the range proposed by others (Burruss et al., 2009; Hovorka et al., 2001). The actual value for capacity factor can be highly site-specific (Bachu et al., 2007) and, as will be illustrated later, can have a considerable impact on storage capacity estimates (Kopp et al., 2009). 
Eq. (1) is a relatively simple model for estimating bulk $\mathrm{CO}_{2}$ capacity. It does not include: (i) cap rock integrity, for which additional characterization would be necessary (Bachu et al., 2007)); (ii) pressure constraints, for we assume that the reservoir will not be overpressurized, which is a conservative assumption (Bachu et al., 2007; Kopp et al., 2009)); or (iii) $\mathrm{CO}_{2}$ dissolution in the pore water, a relatively small influence during the initial injection period (Doughty et al., 2001)). Nonetheless, this type of equation is considered to be reasonably accurate for regional- to national-scale assessments of the trapping potential of large reservoirs (Bachu et al., 2007) such as that being done here.

\subsubsection{Injection module}

The rate at which $\mathrm{CO}_{2}$ can be injected into the aquifer needs to be constrained before the cost of storage can be estimated. The annual injection rate, $Q_{\text {mass }}$, is a function of several geological properties, such as permeability, layer thickness, and porosity, used to solve the radial integration of Darcy's law known as the Theis solution, or the well function (Freeze and Cherry, 1979):

$Q_{\text {mass }}=\rho_{\mathrm{CO}_{2}} \frac{-P_{f} 4 \pi X}{g \rho_{f} \operatorname{Ei}(u)}$

This solution is described in detail in Eccles et al. (2009) and repeated in Section 2 of the Appendix for the interested reader. The solution yields the maximum injection rate below the threshold pressure at which the reservoir will undergo large-scale fracturing based on its geologic properties. We limit the threshold pressure, $P_{f}$, in Eq. (2) to $90 \%$ of the fracturing pressure to account for a safety margin in actual injection projects. We also limit $Q_{\text {mass }}$ to $\leq 3500$ tonnes/day, which is the maximum design rate for the well injection pump at the Sleipner $\mathrm{CO}_{2}$ storage site, an ideal geologic environment for rapidly injecting $\mathrm{CO}_{2}$ (Eccles et al., 2009). We find that without this limit, certain combinations of geologic properties can lead our model to predict injection rates that exceed tens of thousands of tonnes per day, which is not yet technologically feasible. Our injection rate model also assumes that the aquifer is relatively open and homogeneous, which is a simplifying assumption for regional-scale evaluations such as ours, but one that would require closer examination at specific sites.

\subsubsection{Cost module}

The cost module estimates the cost of injection on a per-well basis in dollars per tonne. In our previous study (Eccles et al., 2009), we only considered the cost of drilling and operating the injection well. Here we attempt to include other costs that would be associated with storage, such as site evaluation and monitoring. Our revised cost function is

$C_{i, j}=\frac{1.1 * a_{m} *\left(C_{i, j}^{i n j}\left(z_{i, j}\right)+C_{i, j}^{\text {drill }}\left(z_{i, j}\right)+\frac{C_{i, j}^{\text {site }}}{n_{i, j}^{\text {wells }}}\right)}{Q_{i, j}^{\text {mass }}}$

where $C_{i, j}$ is the levelized annual cost for injection per tonne of $\mathrm{CO}_{2}$, $a_{m}$ is an amortization factor, $C_{i, j}^{i n j}$ and $C_{i, j}^{\text {drill }}$ are the costs of injection equipment and drilling, both of which are a function of depth $(z)$, $C_{i, j}^{\text {site }}$ is the sum of other costs associated with carrying out the injection, $n_{i, j}^{\text {wells }}$ is the number of wells needed to achieve the injection rate, and 1.1 is a scaling factor that accounts for annual operations and maintenance (O\&M) costs( Eccles et al., 2009), based on early work by Bock (2002).

$n_{i, j}^{\text {wells }}$ is determined by taking the annual flux of $\mathrm{CO}_{2}$ emissions being transported to the storage site (i.e. the raster cell) for sequestration, $Q_{s i t e}$, and dividing it by the maximum rate of injection per injection well, $Q_{\text {mass }}$, determined from Eq. (2). Here we assume $Q_{\text {site }}$ to be $10 \mathrm{Mt} / \mathrm{y}$, or the $\mathrm{CO}_{2}$ emissions produced annually by roughly three $500 \mathrm{MW}$ coal-fired power plants; sensitivity tests indicate varying site size between 1 and $25 \mathrm{Mt} / \mathrm{y}$ does not significantly affect the outcome.

The parameter $C_{i, j}^{s i t e}$ includes the costs for site evaluation (e.g. seismic surveys), monitoring and liability, storage-site distribution pipelines, site remediation, and closing costs. We derive these from a report published by the U.S. Environmental Protection Agency (2008), which attempts to constrain all of the major costs associated with geologic sequestration of $\mathrm{CO}_{2}$. The report subdivides these costs into six major components. One of these is termed injection wells, which includes the costs of drilling the well $\left(C_{i, j}^{d r i l l}\right.$, Eq. (4)) and carrying out the injection $\left(C_{i, j}^{i n j}\right.$, Eq. (4)). We calculate these specific costs in our model, and so do not rely on the EPA reported values for them. Each of the remaining component costs is the sum of a series of line-item expenses. These expenses differ from one cost component to the next, and are generally described on a per-unit basis (e.g. $\$ / \mathrm{m}$ depth for drilling costs). For the most part, the expenses in all the components can be grouped into five categories: fixed costs $\left(c_{f i x e d}\right)$, costs per unit area $\left(c_{\text {area }}\right)$, costs per well $\left(c_{\text {well }}\right)$, costs per unit depth $\left(c_{\text {depth }}\right)$, and costs per well per unit depth $\left(c_{\text {well,depth }}\right)$. Each component cost is then arrived at by adding the sum for each expense category after it is converted into US dollars, which is accomplished where necessary by multiplying the category by the appropriate raster variable at the site, i.e.:

$$
\begin{aligned}
C_{i, j}^{k}= & \sum c_{\text {fixed }}^{k}+\left(\sum c_{\text {area }}^{k}\right)\left(\mathrm{Q}_{\text {site }} / \mathrm{A}_{\mathrm{i}, \mathrm{j}}\right)+\left(\sum c_{\text {well }}^{k}\right) n_{i, j}^{\text {wells }} \\
& +\left(\sum c_{\text {depth }}^{k}\right) z_{i, j}+\left(\sum c_{\text {depth }, \text { wells }}^{k}\right) n_{i, j}^{\text {wells }} z_{i, j}
\end{aligned}
$$

Here $k$ represents a specific component cost (e.g., site evaluation) and $A_{i, j}$ is the estimated storage capacity at the grid cell location $i, j$ (for more details, see Appendix Section A2). The second term in Eq. (5) includes the variable capacity, which was missing from our original model (Eccles et al., 2009). Capacity is a critical component in computing the area necessary for a sequestration site and thus its total cost. Site evaluation and monitoring costs in particular are highly dependent on the total area necessary for sequestration.

So too is sufficient well spacing, which is necessary to avoid interference between wells and maintain suitable injection rates over the lifetime of a project (McCoy and Rubin, 2009). In our analysis, the minimum spacing between wells is $\sim 1.7 \mathrm{~km}$ but averages $6.5 \mathrm{~km}$.

The total site costs (in Eq. (5)) are then:

$C_{i, j}^{\text {site }}=\sum_{k=1}^{6} C_{i, j}^{k}$

The dollar costs are adjusted to a 2007 USD basis, for which the PPI for oil and gas is similar to the preliminary PPI in 2010 (Bureau of Labor Statistics (BLS), 2010).

While this new version of our cost module now allows for a more comprehensive estimation of storage costs, we recognize that though regulations for sequestration have been developed in the United States (Environmental Protection Agency (EPA), 2010), site configuration, monitoring, and long-term liability practices for $\mathrm{CO}_{2}$ storage have not yet been established (Benson et al., 2002; Hepple and Benson, 2005). This implies that many of the expenses compiled by the EPA are tentative. Furthermore, a number of these expenses will depend on how the site is evaluated, developed and monitored. As a base case, we assume there is one initial seismic survey to characterize each storage site (i.e. raster cell) and two follow-up monitoring surveys, and that the site is crossed by a relatively high $10 \mathrm{~km}$ of distribution pipelines, in addition to other minor monitoring infrastructure expenses (see Appendix Section A3 for more details as well as for a sensitivity analysis for these assumptions). 


\section{Results}

The capacity and cost estimates produced by our model for the rasterized regions in the 15 deep-saline sandstone aquifers are shown in Fig. 1. As can be seen, some of these regions extend over most of the aquifer and likely reflect its storage potential, while other rasterized regions depict only a fraction of the aquifer and may not be representative of it. Regardless, all of the rasterized regions clarify several important aspects regarding storage capacity/ cost, at least within these aquifers.

The first is that not all areas within the aquifers are suitable for storing $\mathrm{CO}_{2}$ in a supercritical state. The grey portions of the rasterized regions are locations where pressures and/or temperatures within the aquifers do not appear to be sufficient to keep the $\mathrm{CO}_{2}$ supercritical. Generally this occurs where the aquifer is too shallow.

Secondly, locations within the rasterized regions that can support supercritical $\mathrm{CO}_{2}$ storage (colored regions, Fig. 1) have estimated capacities and costs that are not constant. This holds not only from one aquifer to the next, but also within aquifers. For example, storage capacity throughout much of the rasterized region in the Frio aquifer (\#7, Fig. 1a) is high, approaching or exceeding $8 \mathrm{Mt} \mathrm{CO}_{2}$ per grid cell. For the Oriskany aquifer (\#13, Fig. 1a), however, the storage capacity per grid cell is not only an order of magnitude less, but also much more variable, with estimates ranging between $\sim 100 \mathrm{kt}-1 \mathrm{Mt} \mathrm{CO}_{2}$ per grid cell.

A third point is that the variability in storage capacity and cost is not well represented by simple averages. Some aquifers like the Frio and Mt. Simon are dominated by high capacities and low costs, while others exhibit a much more complex mix of capacities and costs, such as in the Oriskany and St. Peter aquifers (\#10 and \# 13, Fig. 1a, respectively). This is even clearer in Fig. 2 and Table 2, which show frequency plots of the estimated storage capacities and costs for the aggregate and selected aquifers as well as a list of summary statistics for all aquifers. These plots (particularly the aggregate data) are non-Gaussian and are largely skewed toward a higher frequency of either lower capacity or lower cost cells with long tails that extend out one or more orders of magnitude. There is a considerable discrepancy between these plots and the average estimated storage capacity and cost for the rasterized regions in the aquifers (see Table 2). The average estimated storage capacity within all the rasters is a relatively high $\sim 500,000$ tonnes $/ \mathrm{km}^{2}$ (median 133,000 tonnes/ $\mathrm{km}^{2}$ ) while the average estimated cost is an extremely high $\$ 106$ / tonne (median $\$ 15.50 /$ tonne). This is the result of the long tails on the frequency plots (Fig. 2, Table 2; see Appendix for Fig. 2 with all basins plotted) biasing the averages upwards and giving the impression that the aquifers have much higher capacities and costs than are evident in the frequency plots, a point we return to later.

Finally, the distributions of estimated capacity and cost in Fig. 1 show a general correspondence with one another. Where the storage estimates are high, such as in the Frio and Mt. Simon rasterized regions, estimated costs tend to be low. And where the storage estimates are on the lower end, such as in rasterized regions within the Oriskany, Lyons and Fox Hills/Lower Hell Creek (\#4, Fig. 1) formations, estimated costs tend to be high.

This inverse relationship, however, is not as strong as it might appear from Fig. 1. Fig. 3 is a scatter plot of storage capacity vs. cost for every grid cell in Fig. 1 where $\mathrm{CO}_{2}$ could be stored in supercritical form (i.e., all the colored cells). The plot shows a clear but very broad trend of lower estimated storage costs for grid cells with higher estimated storage capacity. Note that the plot axes are in log scale, so even though there is a trend, the capacity-cost relationship is still highly variable and appears to be heteroskedastic. For example, at grid cells where storage would approach $\$ 1000 /$ tonne, capacity estimates span $<10^{4}->10^{6} \mathrm{t} / \mathrm{km}^{2}$, while lower costs require cells that could store at least $10^{5} \mathrm{t} / \mathrm{km}^{2}$. Keep in mind that storage sites would consist of multiple grid cells and that sites in low-capacity regions would consist of many more grid cells than those in highcapacity regions, so the density of low-capacity grid cells in this plot is exaggerated relative to high-capacity grid cells. However, the plot does indicate that high storage capacity per unit area is a necessary but not sufficient condition for low cost.

This considerable variability is because estimated cost depends on more than just storage volume. As Eqs. (1) and (2) indicate, other key geologic variables affecting cost are the permeability and depth of the aquifer. Nonetheless, storage volume, and specifically sediment thickness at a site appears to be the most important influence on cost. A linear regression of log-transformed capacity on log-transformed injection layer thickness yields a relationship with an $\mathrm{R}^{2}$ of 0.98 $\left(\mathrm{R}^{2}=0.71-0.99\right.$ for individual formations), while a linear regression of log-transformed cost on log-transformed injection layer thickness yields a relationship with an $\mathrm{R}^{2}$ of 0.62 (from $\mathrm{R}^{2}=0.11-0.99$ for individual formations). This leads us to conclude that layer thickness is a reasonably good site-screening criterion because of the intrinsic link between thickness, high capacity, and low cost.

This link also has an important impact on the marginal abatement cost curves we construct from these estimates. Four MACCs are a

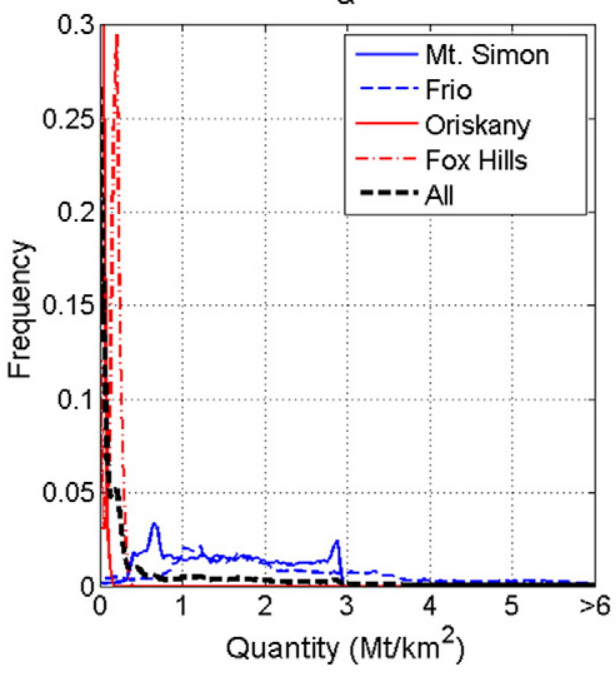

b

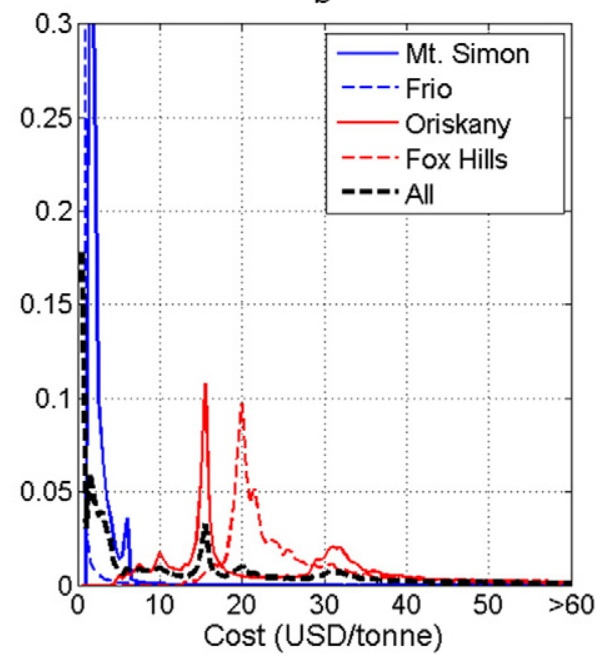

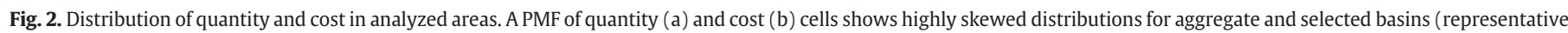
of relatively high (Frio/Mt Simon) and low (Oriskany/Fox Hills) quality). 
Table 2

Summary statistics for capacity and cost for analyzed basins.

\begin{tabular}{|c|c|c|c|c|c|c|c|c|}
\hline & \multicolumn{4}{|c|}{ Capacity (tonnes $/ \mathrm{km}^{2}$ ) } & \multicolumn{4}{|c|}{ Cost (USD/tonne) } \\
\hline & Mean & Median & Min & Max & Mean & Median & Min & Max \\
\hline Mt. Simon & $1,548,029$ & $1,496,750$ & 46 & $2,932,900$ & $\$ 3.57$ & $\$ 2.13$ & $\$ 1.79$ & $\$ 1000$ \\
\hline Frio & $2,327,130$ & $1,924,250$ & 66 & $8,067,400$ & $\$ 1.12$ & $\$ 0.57$ & $\$ 0.44$ & $\$ 1000$ \\
\hline Cape Fear & 105,068 & 49,253 & 17,678 & 523,050 & $\$ 8.28$ & $\$ 8.53$ & $\$ 0.99$ & $\$ 24.11$ \\
\hline Potomac & $1,024,215$ & 951,210 & 363,910 & $2,024,200$ & $\$ 0.75$ & $\$ 0.71$ & $\$ 0.57$ & $\$ 1.24$ \\
\hline Oriskany & 29,795 & 23,573 & 0 & 159,540 & $\$ 180.87$ & $\$ 32.39$ & $\$ 4.88$ & $\$ 1000$ \\
\hline Lyons & 95,332 & 86,246 & 0 & 406,890 & $\$ 303.94$ & $\$ 267.61$ & $\$ 16.59$ & $\$ 1000$ \\
\hline Paluxy & 173,160 & 176,955 & 9094 & 518,020 & $\$ 11.16$ & $\$ 3.31$ & $\$ 1.00$ & $\$ 123.90$ \\
\hline St. Peter & 149,463 & 153,425 & 0 & 321,090 & $\$ 31.37$ & $\$ 5.13$ & $\$ 2.70$ & $\$ 1000$ \\
\hline Granite Wash & 383,129 & 241,760 & 0 & $2,729,200$ & $\$ 99.92$ & $\$ 51.30$ & $\$ 1.89$ & $\$ 1000$ \\
\hline Fox Hills & 180,777 & 201,030 & 5 & 391,380 & $\$ 90.39$ & $\$ 24.40$ & $\$ 13.21$ & $\$ 1000$ \\
\hline Woodbine & 312,126 & 275,980 & 5,936 & 833,200 & $\$ 4.83$ & $\$ 2.23$ & $\$ 0.80$ & $\$ 100.49$ \\
\hline Morrison & 488,668 & 483,095 & 212,020 & 734,580 & $\$ 3.71$ & $\$ 3.40$ & $\$ 2.19$ & $\$ 6.70$ \\
\hline Repetto & 611,236 & 133,060 & 0 & $8,067,400$ & $\$ 104.74$ & $\$ 15.49$ & $\$ 0.44$ & $\$ 1000$ \\
\hline
\end{tabular}

shown in Fig. 4: one for the rasterized region in the Mt. Simon aquifer (\#12, Fig. 1a), another for the region in the Frio aquifer, an aggregate MACC for the remaining basins, and an aggregate MACC for all of the rasterized regions in Fig. 1. Each of these MACCs is in fact depicted as a band of possible estimated capacity-cost curves. This is due to the uncertainty over the distribution of sandy layers within the aquifers. As noted previously, we address this uncertainty by representing the sandy layers as a single unit with a thickness equal to the net sand thickness of the reservoir based on the BEG data. The lower and upper bounds to the MACCs (i.e. the left and ride sides of the bands) are determined by solving for storage capacity and cost when this unit is placed at the bottom and then top of the aquifer, respectively. As the Mt. Simon formation is essentially all sandstone, there is no difference between the two and it is plotted as a line. The difference for the Frio and the total aggregate, however, is considerable.

All four MACCs reflect the non-normal distribution of storage capacities and costs within the rasterized regions. In fact, the MACCs reveal that the bulk of available storage capacity is relatively inexpensive (see Fig. 2). For our base-case scenario, the minimum cost for storage is $\$ 0.50 / \mathrm{t} \mathrm{CO2;} 190$ out of a total of $302 \mathrm{Gt}$ of storage potential are available for less than $\$ 1 / \mathrm{t}$, with nearly $260 \mathrm{Gt}$ at or below $\$ 3 / t$ and almost $275 \mathrm{Gt}$ at or below $\$ 5 / t$. Note that all of these

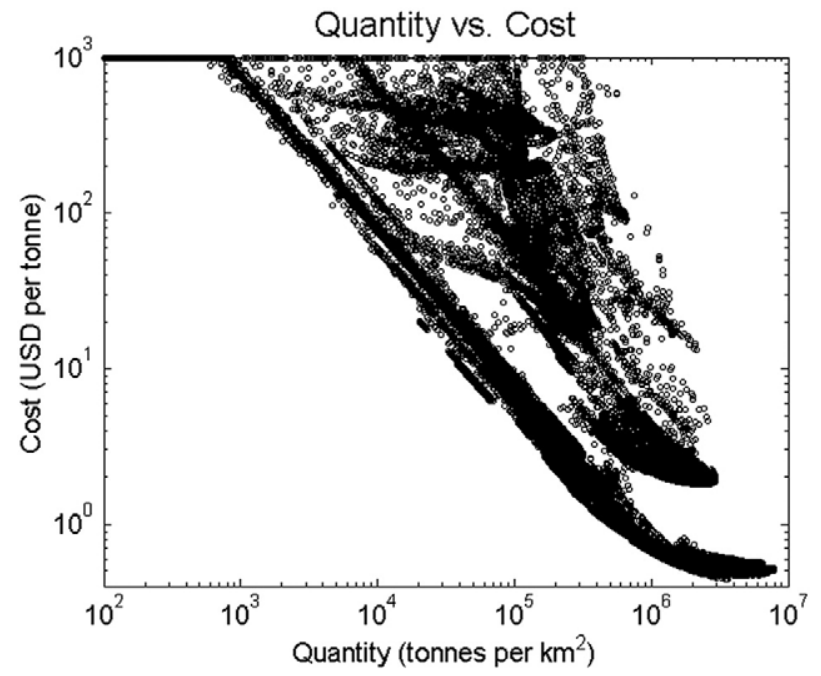

Fig. 3. Cost vs. quantity. A log-log plot of cost vs. quantity shows an inverse power law relationship, with considerable variation to the right of the trend line. The distribution exhibits heteroskedasticity but the variance and skew are both high for all values of the variables. Note that high storage capacity does not guarantee low costs. Only 1 in ten data points $(\sim 50,000$ total $)$ are plotted. costs are considerably lower than the simple average estimated cost of storage mentioned previously, which is $>\$ 100 /$ tonne, and even far below the median, which is $\$ 15.50 /$ tonne.

In fact given the shape of the MACCs, a much more meaningful expression of the average is the cumulative mean cost of storage as a function of cumulative capacity $x$ (i.e. the horizontal axis of Fig. 4)

$\frac{\int_{0}^{x} \operatorname{MACC}(x) d x}{x}$

This function for the aggregate MACC, which represents the average cost of storage at all the sites (i.e. cells) that sum up to a given cumulative capacity, is also plotted in Fig. 4. The function shows that $260 \mathrm{Gt}$ or $87 \%$ of the storage analyzed could potentially be utilized for an mean cumulative cost of $<\$ 1 / \mathrm{t} \mathrm{CO}_{2}$, and that all of the storage could be utilized for a mean cumulative cost of $<\$ 5 / \mathrm{t} \mathrm{CO}_{2}$ (Fig. 4).

The two largest contributors to the aggregate MACC are the Frio and Mt. Simon aquifers. The Frio represents $62 \%$ of all the storage evaluated, while the Mt. Simon constitutes another $21 \%$. This is in

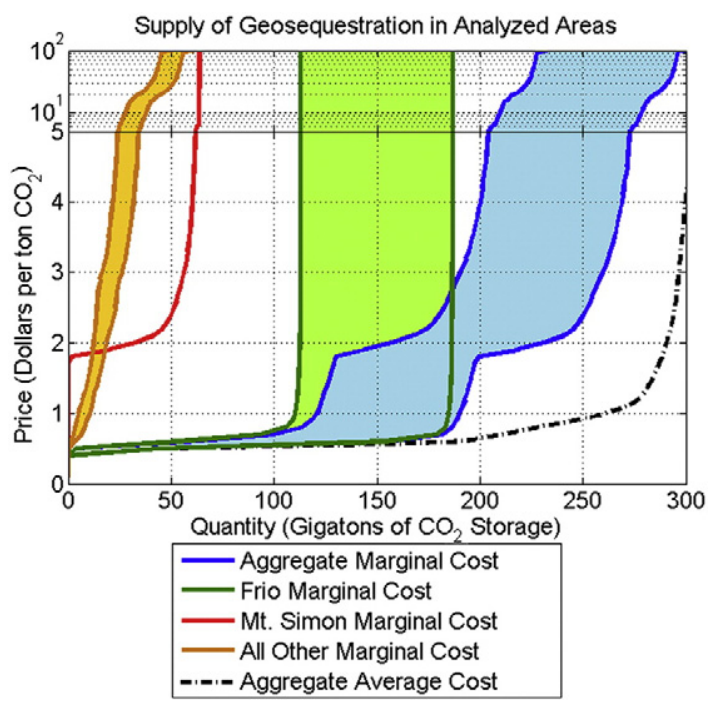

Fig. 4. Aggregate supply function. The curves show the marginal cost of storage within a range bounded by concentrations of sand at the top and bottom of formations for all 15 analyzed formations together, the Frio, Mt. Simon (top and bottom are the same), and the remaining 13 formations. The average cost of abatement for all basins for a layer at the top of a formation (corresponding to the upper bound of the total storage estimate) is also shown. Cost is on a 2007 USD basis and is truncated at $\$ 100$ per tonne. 
part because a number of the other aquifers are underrepresented by the regions we were able to rasterize, including the Glen Canyon, Morrison, and Cape Fear (\#2, \#3 and \#15, Fig. 1a). However, the Frio and Mt. Simon aquifers also overshadow the other aquifers because they have considerable storage capacity at relatively low cost that is far in excess of their surface area. The Frio, for example, makes up only $14 \%$ of all the rasterized areas analyzed, while Mt. Simon makes up only $5 \%$ of the area analyzed, and would dominate the aggregate MACC if the Frio were removed.

Given that they constitute some $83 \%$ of the aggregate MACC, it follows that the Frio and the Mt. Simon aquifers have distributions in which the vast majority of the estimated storage capacity is available at a relatively low estimated cost. In the case of the Frio aquifer, up to $184 \mathrm{Gt}$ of $\mathrm{CO}_{2}$ storage (or $61 \%$ of the storage analyzed) has an estimated cost of $<\$ 1$ for storage only, while in the Mt. Simon aquifer, up to $33 \mathrm{Gt}$ of $\mathrm{CO}_{2}$ storage ( $11 \%$ of the storage analyzed) is estimated to be available for $<\$ 2 /$ tonne. What is significant, however, is that the MACCs for many of the other individual rasters share this same type of distribution (Fig. 2), indicating that while absolute costs may vary between the aquifers, relative costs within the aquifers are similarly distributed, with most available storage clustering near the low end for cost.

This common shape to the MACCs holds even when variables in our model that affect the absolute values of our capacity and cost estimates are changed. Among the least constrained of these variables is the capacity factor. Research by van der Meer et al. (van der Meer and Egberts, 2008; van der Meer and van Wees, 2006), Birkholzer and et al. (Birkholzer and Zhou, 2009; Birkholzer et al., 2009) and Nicot (2008), indicates that the effective capacity factor is reduced if the pressure within the reservoir needs to be managed as it fills with $\mathrm{CO}_{2}$. While our injection module includes pressure constraints, our capacity module does not, so our model may be overestimating storage capacity and in turn underestimating storage costs. We evaluated what impact this might have on the MACCs by reducing the capacity factor eight fold to $0.5 \%$ and then repeating our analysis. In the resulting aggregate MACC, storage costs roughly doubled but the shape of the supply curve remained the same.

We also explored to what degree the shape of our MACC is influenced by the various cost components for the storage site, such as site evaluation and monitoring. Fig. 5 presents the cost distributions for each of these components as estimated from all grid cells in the rasterized regions where supercritical storage of $\mathrm{CO}_{2}$ would be viable. The distributions are displayed as a box-and-whisker plot. In this type of plot, the interquartile range is shown within the boxed region (the 25th to 75th percentiles) with a line for the median, and the whiskers are plotted at 1.5 times this interquartile range beyond the boxes. Outliers are plotted outside the whiskers. In the case of the rasterized regions, all outliers are above the high-cost whiskers and are so numerous that the dots form lines (Fig. 5). This is a direct reflection of the long tails to the total cost distributions shown Fig. 2.

There is considerable variation in the contributions of the different cost components to the total cost, but the estimates summarized in the whisker plot indicate that the injection wells are the most significant cost component in our analysis. For example, the ratio of the median injection cost to the median total cost is $2: 3$. The next two important costs are for site characterization and monitoring; the ratios of these to the median total cost are 1:10 and 1:6, respectively, with the three remaining cost components constituting just 1:12 of the median total cost. Note that in our model, injection well costs (i.e., $C_{i, j}^{d r i l l}$ and $C_{i, j}^{i n j}$ in Eq. (4)), which dominate the total estimated cost for storage, are a function of site geology. Site geology is also the fundamental control on the shape of our MACC. Thus we conclude that varying the component costs will affect the absolute estimates for storage costs produced by our model, but not significantly alter the distribution of costs represented in our MACC.

\section{Discussion}

Our storage-based MACCs of select regions within a number of deep-saline sandstone aquifers reveal that, at least in the regions

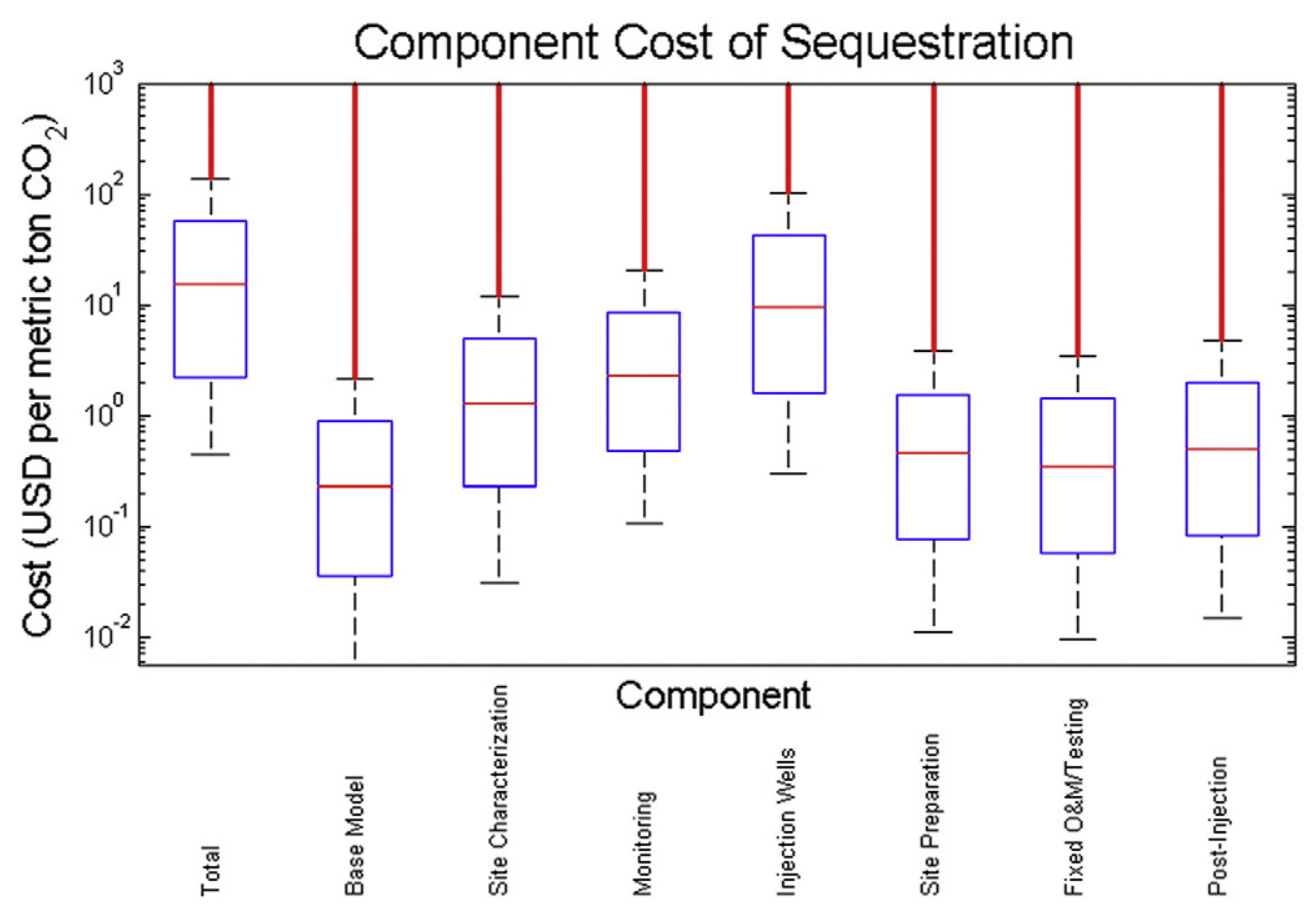

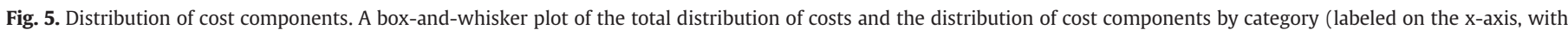

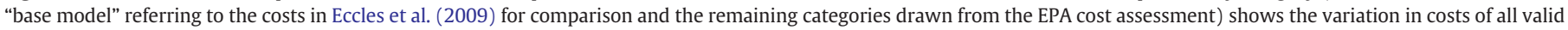

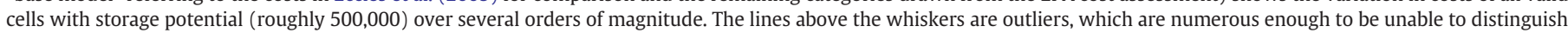
them individually. 
we have analyzed, areas with high estimated storage capacity also tend to have low estimated storage cost. This connection persists even when variables that have a strong influence on the cost estimates produced by our model are changed substantially.

Two other factors could affect the shape of our MACCs, one of which is the accuracy of our model in predicting storage capacity and injection rates. This accuracy is discussed at length in Eccles et al. (2009) where among other things we found that our predictions of injection rates for geologic conditions approximate those at current $\mathrm{CO}_{2}$ storage demonstration projects (i.e. Sleipner West, Frio, Nagaoka) fall within the injection rate limits reported at these projects. We also do not directly consider the option of pumping brine water to enhance injectivity, although this may only be necessary if our assumption that wells have sufficient drainage radius is incorrect and would simply add to the base cost of injection. We also discussed, as we do in this paper, how our capacity module is similar to that developed by others. This module is also similar to that used in NATCARB for estimating the storage capacity of the same deep-saline sandstone reservoirs analyzed here. A direct comparison of the estimates is not appropriate given differences between the studies in the spatial extent to which the aquifers were evaluated. But our storage estimates for these reservoirs are in line with those reported by NATCARB (see Table 3), which likewise shows vast storage potential in the Mt Simon and along the Texas Gulf Coast, and similar to other studies (Bachu, 2003; Department of Energy (DOE), 2010). These similarities plus the favorable comparison of our injection rate estimates with data from demonstration projects suggests the shape of the MACCs in Fig. 4 is unlikely to result from potential problems with our model.

Another factor that could affect the shape of the MACCs is the inclusion of additional aquifer areas and even other aquifers in our analysis. For example, the BEG dataset underrepresents the Mt. Simon formation, which could rival the Frio in storage potential (Barnes et al., 2009). And because our current model is for sandstone aquifers, we do not address the storage potential of deep-saline carbonate aquifers, which calculations by the BEG (2000) and NATCARB (Department of Energy (DOE), 2010) suggest could have storage capacities approaching those of the Mt. Simon and Frio aquifers.

Inclusion of more aquifer regions would raise the absolute storage capacity in our MACC, but it is unclear whether additional data on these or other aquifers would also significantly alter the shape of the MACC. We find no significant correlation between the considerable variation in density of the BEG data and our estimates of storage capacity and cost. This suggests that while increased data density is likely to refine our capacity estimates for the aquifers, it will not necessarily change the weighting of the MACC toward high-capacity/ low-cost storage. Furthermore, inclusion of more low-capacity/highcost regions in our analysis (those represented by the right, upward rising side of the MACC) is not likely to add enough storage capacity to diminish the extent of high-capacity/low-cost regions already included in the MACC (i.e. shift the curve left). And the inclusion of more high-capacity/low-cost regions (the flat, left side of the MACC) will simply enhance the current shape of the MACC by increasing the cumulative capacity of low-cost storage areas (i.e. shift the curve right).

Where additional and/or improved data could have a significant impact on our results, however, is in the spatial distribution of storage capacity shown in Fig. 1. If these data were to reveal different capacity patterns within the aquifers due to for example new formations and/ or changes in porosity, the locations of the high-quality, low-cost regions within the aquifers could shift with respect to the locations of major $\mathrm{CO}_{2}$ point sources in the U.S. This in turn could have a significant impact on CCS transport costs if the revised data indicates these sources are located farther away from viable storage sites (McCoy and Rubin, 2009; Gresham et al. 2010), reinforcing conclusions that the acquisition of more accurate geological data is a valuable investment (Friedmann et al., 2006).

An underlying cause for the shape of the MACC appears to be that cost and capacity are inversely related through the net sand thickness of the reservoir. Thick reservoirs have high bulk volume and can physically store the most $\mathrm{CO}_{2}$, so they will make up the majority of storage in a sink-based MACC. Thick reservoirs will also be relatively low cost because the major cost components depend on injection rate ( $Q_{\text {mass }}$ through $Q_{\text {site }}$ and $n$ in Eq. (5)), which increases with net sand thickness, and they depend on the area over which the plume of injected $\mathrm{CO}_{2}$ will spread away from the injection well $\left(A_{i, j}\right.$ in Eq. (5)), which decreases with net sand thickness. It is certainly possible that some reservoir regions may be low-cost because of high permeability. However, unless these regions are also thick, their bulk volume will be low and their affect on the MACC will not be significant. For the same reasons, high cost, low-capacity regions will also not have a significant affect on the MACC. Consequently, we believe that this connection between relatively high-capacity and low-cost storage is likely to be one of our most robust results, a promising conclusion for proponents of CCS if correct.

As stated previously, however, CCS will only see widespread deployment if it is cost effective, and probably the most tentative estimates produced by our model are those relating to costs. Our estimates are almost certainly not an upper bound on storage costs. As previously stated, site configuration, monitoring, and long-term liability practices have not yet been established (Benson et al., 2002; Hepple and Benson, 2005), and we do not include other

Table 3

Comparison of capacity estimates with NATCARB.

\begin{tabular}{|c|c|c|c|c|c|}
\hline \multirow{2}{*}{$\begin{array}{l}\text { Map } \\
\text { index }\end{array}$} & \multirow[t]{2}{*}{ Formation } & \multicolumn{3}{|c|}{ Storage (billion metric tons) } & \multirow[t]{2}{*}{ Notes } \\
\hline & & Total estimate & NATCARB low & NATCARB high & \\
\hline 1 & Repetto & 0.16 & 1 & 35 & From plot \\
\hline 2 & Glen Canyon & 0 & & & Evaluated by state; not listed \\
\hline 3 & Morrison & 0.73 & & & Evaluated by state; not listed \\
\hline 4 & Fox Hills & 5.7 & & & Our spatial extent not listed \\
\hline 5 & Lyons & 5.5 & & & Evaluated by state; not listed \\
\hline 6 & Granite Wash & 9.4 & & & Evaluated by state; not listed \\
\hline 7 & Frio & 187 & 17 & 235 & \\
\hline 8 & Woodbine & 10.8 & 5 & 70 & 8 and 9 listed as combined \\
\hline 9 & Paluxy & 1.7 & 5 & 70 & \\
\hline 10 & St Peter & 7.9 & 0.6 & 7.8 & \\
\hline 11 & Pottsville & 0 & 1.1 & 15 & \\
\hline 12 & Mt Simon & 64 & 17 & 68 & \\
\hline 13 & Oriskany & 4.4 & 0.7 & 2.9 & \\
\hline 14 & Cape Fear & 1.2 & 12.6 & 60 & Formation may not match \\
\hline 15 & Potomac & 3.8 & 2 & 25 & \\
\hline 16 & Tuscaloosa & & 5 & 75 & \\
\hline
\end{tabular}


potentially significant expenses such as compensating property owners (Gresham et al., 2010). Other factors beyond the scope of this study can also affect costs, such as obtaining legal rights to the pore space needed for storage, estimates for which range between $\$ 0.4$ and $\$ 11 / \mathrm{tCO}_{2}$ (Duncan et al., 2009; Gresham et al., 2010). Nonetheless, our assumptions and modeling yield average storage costs that are close to those arrived at by Middleton and Bielicki (2009) using a similar injection model for a fixed set of geological properties, and our ranges for storage costs evaluating a wider set of properties are similar to those of Wildenborg et al. (2004). In fact, we are able to find previous cost estimates for $\mathrm{CO}_{2}$ storage that range over much of our MACC (AL-JUAIED and Whitmore, 2009; Allinson et al., 2003; BCG, 2008; Bock, 2002; Hendriks et al., 2004; McKinsey Climate Change Initiative, 2008). This is because nearly all of the costs reported, from the $<\$ 1$ tonne/y in Bock (2002) to the $>\$ 10$ tonne/y in Al-juaied and Whitmore (2009), are reasonable given some geological parameters. Therefore, the problem lies not necessarily with the methodology for calculating these costs but rather the manner in which they are reported, which to date has been in terms of simple mean costs or even costs derived from reservoir properties at a single wellsite. For example, in our previous paper (Eccles et al., 2009), we did not account for the spatial distribution of the aquifer properties we analyzed and arrived at an "average" storage cost of $\sim$ \$ tonne, a figure that was in line with others' estimates. Here we do account for the spatial distribution of the reservoir properties and when we calculate a simple average cost as before, we arrive at $>\$ 100 /$ tonne. Only when the capacities and costs are considered together in a spatial framework does it become clear that low-cost regions are also high-capacity regions, meaning that much of the storage capacity of the aquifers we evaluated is estimated to be low cost. And because the capacity and cost distributions are not uniform, simple averages are not only inaccurate, they can lead to an overestimate in the cost of storage in aquifers with considerable geologic heterogeneity.

Simple averages or single estimates of storage capacity and cost are also misleading in terms of where to sequester $\mathrm{CO}_{2}$ in aquifers. Many of the rasterized regions in Fig. 1 have sub-regions of highcapacity/low-cost storage that occur in different parts of an aquifer. Linking these higher quality storage sites to $\mathrm{CO}_{2}$ point sources via pipelines could require different transport routes and thus transport distances to the aquifers. To date, studies using transport modeling have done the best job integrating the cost of transportation and storage. Middleton and Bielicki(2009), McCoy and Rubin (2008), and Wildenborg et al. (2004) among others have developed transport optimization algorithms that can take into account geologic and economic differences between storage sites. The disclosure of costs in these studies, however, is generally in the form of summary statistics (e.g. mean and standard deviation (Middleton and Bielicki, 2009)), which as we have discussed can under-represent the true variation in storage costs, and assumes them to be normally distributed, which is probably incorrect. Other studies give no hint that spatial or geological variability is even considered. Supply curves (representing integrated costs of storage and transport, compiled by a different method than ours) for North America and China by Dooley et al. (2004) and Dahowski et al. (2009), respectively, rely on a method for characterizing cost in all saline aquifers based on a single value for injection rate (computing injection cost only) and never disentangle the cost of storage in saline aquifers from transport except for two examples (with the same cost of storage) shown graphically in a subsequent report (Dooley et al., 2008).

If the cost of storage varies on the same scale as the cost of transport reported in literature, which our analysis supports, the optimal transport configuration must take into account variations in storage capacity (Gresham et al., 2010; McCoy and Rubin, 2008; Middleton and Bielicki, 2009). Without differentiating the cost at the end of the transport stage, the transport optimization algorithm will not map cost-efficient or possibly even practical routes for transporting
$\mathrm{CO}_{2}$ from sources to sinks. The algorithm will also not calculate the integrated cost of transport and storage correctly. Variability in storage costs is therefore important in determining both the overall viability of the integrated CCS system as well as the ultimate configuration of the transport-storage components of the system.

A few regions with relatively high-capacity, low-cost storage potential dominate the bulk of the MACC in our analysis. These regions constitute some $83 \%$ of the storage potential, but only $19 \%$ of the total surface area of the aquifer regions we analyzed. The remainder tends to have lower storage capacity at higher estimated cost. Our analysis is limited, however, and should not be used to exclude regions of the country as not having good storage potential. There are undoubtedly sites within many of these lower quality aquifers that when transportation expenses are included could still prove to be cost-effective storage sites for certain $\mathrm{CO}_{2}$ point sources.

Our analysis does suggest that not all $\mathrm{CO}_{2}$ sources will have cheap transport access to high-quality storage sites. If this is the case, the configuration of the national transport and storage system might look quite different than a set of shortest pathways from $\mathrm{CO}_{2}$ sources to a relatively homogenous group of saline aquifers such as that depicted by Dooley et al. (2004). In fact, with the incorporation of more and better data, our storage-based maps and MACCs would have greater value as a component of the type of comprehensive transport modeling conducted by Dooley et al. (2004). Integrated assessments of the entire CCS system will be more accurate when the vast heterogeneity in geosequestration potential in saline aquifers is taken into account. This improvement will better inform policymakers and industry on the true potential, costs and configuration of CCS as an emissions abatement option.

\section{Acknowledgements}

The authors would like to acknowledge the assistance of Eric Williams, Peter Haff and Timothy Johnson. This research was supported by the DOE under DE-FOA-0000032 (JE and LP), the Department of Energy's National Energy Technology Laboratory under DE-FE0002197 (RJ), and the Climate Change Policy Partnership.

\section{Appendix A. Supplementary data}

Supplementary data to this article can be found online at doi:10. 1016/j.eneco.2011.11.015.

\section{References}

Al-Juaied, M., Whitmore, A., 2009. Realistic Costs of Carbon Capture (Discussion Paper). Belfer Center for Science and International Affairs,Harvard Kennedy School.

Allinson, W.G., Nguyen, D.N., Bradshaw, J., 2003. The economics of geological storage of CO2 in Australia. APPEA J. 623.

Bachu, S., 2003. Screening and ranking of sedimentary basins for sequestration of $\mathrm{CO} 2$ in geological media in response to climate change. Environ. Geol. 44, 277-289.

Bachu, S., Bonijoly, D., Bradshaw, J., Burruss, R., Holloway, S., Christensen, N.P., Mathiassen, O.M., 2007. CO2 storage capacity estimation: methodology and gaps. Int. J. Greenhouse Gas Control 1, 430-443.

Bahr, D.B., Hutton, E.W.H., Syvitski, J.P.M., Pratson, L.F., 2001. Exponential approximations to compacted sediment porosity profiles. Comput. Geosci. 27, 691-700.

Barnes, D.A., Bacon, D.H., Kelley, S.R., 2009. Geological sequestration of carbon dioxide in the Cambrian Mount Simon Sandstone: regional storage capacity, site characterization, and large-scale injection feasibility, Michigan Basin. Environ. Geosci. 16, 163-183.

BCG, 2008. Carbon Capture and Storage: A Solution to the Problem of Carbon Emissions. Boston Consulting Group.

Benson, S.M., Hepple, R.P., Apps, J., Tsang, C.-F., Lippmann, M., 2002. Lessons Learned from Natural and Industrial Analogues for Storage of Carbon Dioxide in Deep Geological Formations ( No. LBNL Paper LBNL-51170). Lawrence Berkeley National Laboratory, Lawrence Berkeley National Laboratory.

Bernstein, L., Bosch, P., Canziani, O., Chen, Z., Christ, R., Davidson, O., Hare, W., Huq S., Karoly, D., Kattsov, V., et al., 2007. Climate Change 2007: Synthesis Report. An Assessment of the Intergovernmental Panel on Climate Change. Cambridge University Press.

Birkholzer, J.T., Zhou, Q., 2009. Basin-scale hydrogeologic impacts of CO2 storage: capacity and regulatory implications. Int. J. Greenhouse Gas Control 3, 745-756. 
Birkholzer, J.T., Zhou, Q., Tsang, C.-F., 2009. Large-scale impact of CO2 storage in deep saline aquifers: a sensitivity study on pressure response in stratified systems. Int. J. Greenhouse Gas Control 3, 181-194.

Bock, B., 2002. Economic Evaluation of CO2 Storage and Sink Enhancement Options EPRI, TVA, U.S. DOE, Palo Alto, CA; Muscle Shoals, AL; Washington, DC.

Bureau of Economic Geology (BEG), 2000. Carbon-dioxide sequestration [WWW Document]. Carbon dioxide sequestration-study areas URL http://www.beg. utexas.edu/environqlty/co2seq/co2data.htm2000.

Bureau of Labor Statistics (BLS), 2010. Producer Price Index Database ( No. PCU211-211-), Producer Price Index Industry Data. U.S. Department of Labor, Washington, DC.

Burruss, R., Brennan, S.T., Freeman, P.A., Merrill, M.D., Ruppert, L.F., Becker, M.F. Herkelrath, W.N., Kharaka, Y.K., Neuzil, C.E., Swanson, S.M., Cook, T.A., Klett, T.R., Nelson, P.H., Schenk, C.J., 2009. Development of a probabilistic assessment methodology for evaluation of carbon dioxide storage. U.S. Geological Survey OpenFile Report No. OFR 2009-1035. U.S. Geological Survey, Reston, Virginia.

Dahowski, R.T., Li, X., Davidson, C.L., Wei, N., Dooley, J.J., Gentile, R.H., 2009. A preliminary cost curve assessment of carbon dioxide capture and storage potential in China. Energy Procedia 1, 2849-2856.

Department of Energy (DOE), 2010. Carbon Sequestration Atlas of the United States and Canada Online (III). National Energy Technology Laboratory, Morgantown, WV.

Dooley, J.J., Dahowski, R.T., Davidson, C.L., Bachu, S., Gupta, N., Gale, J., 2004. A CO2 storage supply curve for North America and its implications for the deployment of carbon dioxide capture and storage systems. Proceedings of the Seventh International Conference on Greenhouse Gas Control Technologies. Presented at the Seventh International Conference on Greenhouse Gas Control Technologies. Elsevier, Amsterdam, Netherlands.

Dooley, J.J., Dahowski, R.T., Davidson, C.L., 2008. On the Long-Term Average Cost of CO2 Transport and Storage ( No. PNNL-17389). Pacific Northwest National Laboratory, Richland, WA.

Doughty, C., Pruess, K., Benson, S.M., Hovorka, S.D., Knox, P.R., Green, C.T., 2001. Capacity investigation of brine-bearing sands of the Frio formation for geologic sequestration of CO2 ( No. LBNL Paper LBNL-48176). Lawrence Berkeley National Laboratory, Lawrence Berkeley National Laboratory.

Duncan, I.J., Nicot, J.-P., Choi, J.-W., 2009. Risk Assessment for future CO2 Sequestration Projects Based CO2 Enhanced Oil Recovery in the U.S. Energy Procedia 1, 2037-2042.

Eccles, J.K., Pratson, L., Newell, R.G., Jackson, R.B., 2009. Physical and economic potential of geological CO2 storage in saline aquifers. Environ. Sci. Technol. 43, 1962-1969.

Environmental Protection Agency (EPA), 2008. Geological CO2 Sequestration Technology and Cost Analysis (Technical Support Document No. EPA 816-B-08-009). EPA Office of Water, Washington, DC.

Environmental Protection Agency (EPA), 2010. Federal requirements Under the Underground Injection Control (UIC) program for carbon dioxide (CO[bdi2]) geologic sequestration (GS) wells; final rule.

Freeze, R.A., Cherry, J.A., 1979. Groundwater.

Friedmann, S.J., Dooley, J.J., Held, H., Edenhofer, O., 2006. The low cost of geological assessment for underground $\mathrm{CO} 2$ storage: policy and economic implications. Energy Convers. Manage. 47, 1894-1901.

Gresham, R.L., McCoy, S.T., Apt, J., Morgan, M.G., 2010. Implications of compensating property owners for geologic sequestration of CO2. Environ. Sci. Technol. 44, 2897-2903.

Hendriks, C., Graus, W., van Bergen, F., 2004. Global carbon dioxide storage potential and costs ( No. EEP-02001). Ecofys, Utrecht.
Hepple, R.P., Benson, S.M., 2005. Geologic storage of carbon dioxide as a climate change mitigation strategy: performance requirements and the implications of surface seepage. Environ. Geol. 47, 576-585.

Hoffert, M.I., Caldeira, K., Benford, G., Criswell, D.R., Green, C., Herzog, H., Jain, A.K., Kheshgi, H.S., Lackner, K.S., Lewis, J.S., Lightfoot, H.D., Manheimer, W., Mankins, J.C., Mauel, M.E., Perkins, L.J., Schlesinger, M.E., Volk, T., Wigley, T.M.L., 2002. Advanced technology paths to global climate stability: energy for a greenhouse planet. Science 298, 981-987.

Holloway, S., Garg, A., Kapshe, M., Deshpande, A., Pracha, A.S., Khan, S.R., Mahmood, M.A., Singh, T.N., Kirk, K.L., Gale, J., 2009. An assessment of the CO2 storage potential of the Indian subcontinent. Energy Procedia 1, 2607-2613.

Hovorka, S.D., Doughty, C., Knox, P.R., Green, C.T., Pruess, K., Benson, S.M., 2001. Evaluation of brine-bearing sands of the Frio Formation, Upper Texas Gulf Coast for geological sequestration of CO2. University of Texas at Austin, Austin, TX.

IPCC, 2005. Carbon Capture and Storage. Cambridge University Press.

Koide, H., Tazaki, Y., Noguchi, Y., Nakayama, S., Iijima, M., Ito, K., Shindo, Y., 1992. Subterranean containment and long-term storage of carbon dioxide in unused aquifers and in depleted natural gas reservoirs. Energy Convers. Manage. 33, 619-626.

Kopp, A., Class, H., Helmig, R., 2009. Investigations on CO2 storage capacity in saline aquifers-part 2: estimation of storage capacity coefficients. Int. J. Greenhouse Gas Control 3, 277-287.

McCoy, S.T., Rubin, E.S., 2008. An engineering-economic model of pipeline transport of $\mathrm{CO} 2$ with application to carbon capture and storage. Int. J. Greenhouse Gas Control 2, 219-229.

McCoy, S.T., Rubin, E.S., 2009. Variability and uncertainty in the cost of saline formation storage. Energy Procedia 1, 4151-4158.

McKinsey Climate Change Initiative, 2008. Carbon Capture \& Storage: Assessing the Economics. McKinsey \& Company.

Middleton, R.S., Bielicki, J.M., 2009. A scalable infrastructure model for carbon capture and storage: SimCCS. Energy Policy 37, 1052-1060.

Nicot, J.-P., 2008. Evaluation of large-scale $\mathrm{CO} 2$ storage on fresh-water sections of aquifers: an example from the Texas Gulf Coast Basin. Int. J. Greenhouse Gas Control 2, 582-593.

Nordbotten, J.M., Celia, M.A., Bachu, S., 2005. Injection and storage of $\mathrm{CO} 2$ in deep saline aquifers: analytical solution for $\mathrm{CO} 2$ plume evolution during injection. Transp. Porous Media 58, 339-360.

Pacala, S., Socolow, R., 2004. Stabilization wedges: solving the climate problem for the next 50 years with current technologies. Science 305, 968-972.

Span, R., Wagner, W., 1996. A new equation of state for carbon dioxide covering the fluid region from the triple-point temperature to $1100 \mathrm{~K}$ at pressures up to 800 MPa. J. Phys. Chem. Ref. Data 25, 1509-1596.

van der Meer, B., Egberts, P., 2008. Calculating subsurface CO2 storage capacities. Leading Edge 27, 502-505.

van der Meer, L., van Wees, J.-D., 2006. Limitations to storage pressure in finite saline aquifers and the effect of $\mathrm{CO} 2$ solubility on storage pressure. Proceedings of SPE Annual Technical Conference and Exhibition. Presented at the SPE Annual Technical Conference and Exhibition.

Wildenborg, T., Gale, J., Hendriks, C., Holloway, S., Brandsma, R., Kreft, E., Lokhorst, A., 2004. Cost curves for CO 2 storage: European sector. Proceedings of the 7th International Conference on Greenhouse Gas Control Technologies (GHGT-7), September, pp. 5-9. 